\title{
PENGEMBANGAN MATERI AJAR BERBASIS COOPERATIVE INTEGRATED READING AND COMPOSITION (CIRC) UNTUK KETERAMPILAN QIRO'AH DI MTS TANWIRUL ISLAM
}

\author{
Moh. Hasyim Asy'ari \\ STAI Nazhatut Thullab Sampang Jl.Diponegoro No. 11 Sampang \\ Email : hasyimmoh5@gmail.com
}

\begin{abstract}
Abstrak:
Topik penelitian ini adalah "Pengembangan Materi Berbasis Cooperative Integrated Reading and Composition (CIRC) untuk Keterampilan Qiro'ah di MTs Tanwirul Islam". MTs Tanwirul Islam menetapkan pembelajaran keterampilan Qiro'ah pada hari Selasa jam 2 dan 3. Dalam penerapannya MTs Tanwirul Islam menghadapi beberapa permasalahan, di antaranya: 1.Model pembelajaran yang digunakan guru di dalam kelas kurang efektif seperti model pempelajaran ceramah sehingga tidak adanya keikut sertaan siswa dalam proses pembelajaran yang menyebabkan siswa merasa bosan dan pembelajarannya menjadi tidak efektif, 2.Materi ajar untuk kemahiran berbicara bahasa Arab yang digunakan selama ini masih bersifat konvesional. Dan penulis mencoba memecahkan permasalahan ini dengan Cooperative Integrated Reading and Composition (CIRC). Karena Cooperative Integrated Reading and Composition (CIRC) adalah model pembelajaran yang efektik dan memudahkan siswa untuk memahami teks qiroah.. Adapun tujuan dari penelitian ini adalah: 1.Untuk memahami cara mengembangkan Materi Ajar dengan Asas Cooperative Integrated Reading and Composition (CIRC) untuk Keterampilan Qiro'ah, 2.Untuk memahami karakteristik Materi Ajar dengan Asas Cooperative Integrated Reading and Composition (CIRC) untuk Keterampilan Qiro'ah, 3.Untuk memahami sejauh mana efektivitas Materi Ajar dengan Asas Cooperative Integrated Reading and Composition (CIRC) untuk Keterampilan Qiro'ah. Dalam penulisan jurnal ini peneliti menggunakan metode penelitian dan pengembangan. Yaitu, sebuah metode yang digunakan untuk menghasilkan produk tertentu dan menguji efektivitas produk. Untuk menyelesaikan penelitian ini peneliti menggunakan langkah-langkah penelitian dan pengembangan dari Borg dan Gall. Hasil penelitian ini adalah sebagai berikut: 1.Penelitian ini terselesaikan dengan langkah-langkah berikut: penelitian pendahuluan, pengumpulan data, desain produk, validasi ahli, revisi produk, uji produk kelompok kecil, revisi produk, uji efektivitas, penyempurnaan produk akhir, dan diseminasi, 2.Adapun karakteristik dari buku ajar ini adalah: nama buku "Ayo Belajar Bahasa Arab". Buku ini terdiri dari kosa kata, teks bacaan, evaluasi, tata bahasa serta permainan bahasa, 3.Hasil dari Asymp.sig.(2tailed) bernilai 0,001 karena nilai 0,001 lebih kecil dari <0,05 maka disimpulkan Ha diterima, artinya ada perbedaan yang signifikan antara pre-test dan Post-tes. yang artinya materi ajar yang dikembangkan memiliki pengaruh yang sangat besar (signifikan) atau sangat efektif untuk keberhasilan pembelajaran Qiro'ah.
\end{abstract}


Kata Kunci: Pengajaran, kemahiran membaca, Cooperative Integrated Reading and Composition (CIRC)

\begin{abstract}
:
The topic of this research is "Development of Teaching Materials with Cooperative Integrated Reading and Composition (CIRC) Principles for Reading Comprehension in MTs Tanwirul Islam. MTs Tanwirul Islam establishes reading literacy learning on Tuesday at 2 and 3 hours. In its implementation MTs Tanwirul Islam faces several problems, among them: 1.when Arabic teacher teaching materials qiroah is not good because the instructional model used by teachers in the class is not as effective as the lecture model so that the absence of student participation in the learning process so that students feel bored and Learning becomes ineffective, 2.The teaching materials for Arabic speaking skills used so far are still conventional. And the author tries to solve this problem with Cooperative Integrated Reading and Composition (CIRC). Because the Cooperative Integrated Reading and Composite (CIRC) is an effective learning model and allows students to understand the text of qiroah .. The purpose of this study are: 1.To understand how to develop Teaching Materials with Cooperative Integrated Reading and Composition (CIRC) Principles for Proficiency Read, 2.To understand the characteristics of the Teaching Material with the Cooperative Integrated Reading and Composition (CIRC) Principles for Reading Proficiency, 3.To understand the extent of the effectiveness of the Teaching Material with the Cooperative Integrated Reading and Composition (CIRC) Principles for Reading Proficiency. In this journal writing researcher use research and development method. That is, a method used to produce a particular product and test its effectiveness. And to complete this research the researchers used the research and development steps of Borg and Gall. And the results of this study are as follows: 1.This study is completed by the following steps: preliminary research, data collection, product design, expert validation, product revision, small product group test, product revision, effectiveness test, final product refinement, and Dissemination. 2.The characteristics of this textbook are: the name "Let's Learn Arabic". This book consists of vocabulary, text reading, evaluation, tarkib and language game. 3. The result of Asymp.sig. (2tailed) is 0.001 because the value of 0.001 is less than $<0.05$ then it is concluded Ha is accepted, it means there is a significant difference between pre-test and Post-test. Which means that the developed textbook has a very large (significant) or very effective effect on the success of learning reading
\end{abstract}

Keywords: Teaching, reading comprehension, Cooperative Integrated Reading and Composition (CIRC).

\title{
Pendahuluan
}

Bahasa arab mempunyai empat keterampilan yaitu keterampilan membaca, menulis, berbicara dan mendengar. Adapun keterampilan membaca mempunyai keunggulan tersendiri dari empat keterampilan lainya, maka keterampilan membaca merupakan salah satu bidang kegiataan yang paling penting. Diantara salah satu keunggulan keterampilan membaca adalah alat untuk mendapatkan 
pengetahuan yang di dalamnya terdapat informasi terbaru bagi mereka yang lancar bacaanya dan paham terhadap apa yang di baca.

Membaca merupakan sistem pembelajaran yang terdapat penekanan dalam pembelajarannya berdasarkan sistem keterampilan bertahap. Di mulai dari keterampilan yang sederhana sampai ke yang rumit, maka sebagian kegiatan pembelajaran menekankan pada bacaan lafadnya dan sebagian yang lain menekankan dalam segi pemahaman atau penekanan terhadap keduanya secara bersamaan. ${ }^{1}$

Permasalahan yang ditemukan adalah materi ajar yang diajarkan kurang baik dan isinya tidak sesuai dengan kemampuan siswa, seperti halnya hasil wawancara dengan guru bahasa arab di sekolah tersebut mengatakan materi ajar Qiro'ah terlalu sulit bagi siswa dan tidak sesuai dengan kemampuan siswa. ${ }^{2}$

Peneliti mengobservasi peroses pembelajaran, ketika peroses pembelajaran peneliti menemukan bahwa dalam pembelajaran Qiro'ah, metode yang dipakai oleh guru seperti metode ceramah kurang efektif, karena minimnya kesempatan bagi siswa untuk ikut serta dalam kegiatan pembelajaraan sehingga menyebabkan siswa merasa bosan. Hasil observasi dikuatkan dengan hasil wawancara terhadap siswa yang bernama Abd.Rohman: kami merasa bosan ketika pembelajaran Qiro'ah, oleh sebab itu kami ingin belajar Qiro'ah dengan berkelompok. Dengan beberapa alaan diatas peneliti berasumsi perlunya pengembangan materi ajar untuk pembelajaran Qiro'ah.

Berdasarkan informasi tersebut peneliti ingin mengembangkan materi ajar dengan berbasis Cooperative Integrated Reading and Composition (CIRC) karena asas terseebut sesuai dengan permasalahan yang ada saat ini dan juga asas tersebut cocok untuk mengasah keterampilan membaca siswa. Maka Topik yang akan di bahas dalam penelitian ini adalah "Pengembangan Materi Berbasis Cooperative Integrated Reading and Composition (CIRC) untuk keterampilan Qiro'ah di MTs Tanwirul Islam"

\section{Kajian Teoretik}

Kata Tatwir mengikuti wazan Fa'alun yang berarti pengembangaan. ${ }^{3}$ Menurut Dewantoro pengembangan adalah suatu keegiatan untuk menghasilkan sesuatu. ${ }^{4}$ Artiya kegiaatan pengembanngan dengan perancangan, uji coba dan penyempurnaan. ${ }^{5}$

Materi ajar adalah bahan ajar yang diberikan kepada siswa untuk tercapainya tujuan pembelajaran baik afektif maupun psikomotorik. Rosyid Ahmad Tu'aimah mengatakan bahwa materi ajar adalah sekumpulan berita pendidikan, realita dan pengetahuan-pengetahuan yang diberikaan kepada siswa serta arahan dan nilai yang di inginkan untuk pengembangan kemampuan siswa atau keterampilan motorik yang di perolehnya denngan tujuan mengokohkan

\footnotetext{
${ }^{1}$ Toha Ali Husin Addalimiy wa Sa'ad Abi Al-karim Al-Waliy, Ittijahat hadisati fi tadrisAa-Luuhha AlAarobiyah, (Al- Ardan: Alimu Al-kitab Al-hadist, 2009), 3-4.

2Juwairiyah Guru Bahasa Arab MTs Tanwirul Islam, Wawancara Lagsung,, 23 februari 2018.

${ }^{3}$ Ahmad Warson Munawir dan Muhammad Fairuz, Al- Munawwir: Kamus Indonesia-Arab (Yogyakarta: Pustaka progresif, 2007), 419.

${ }^{4}$ Burhan Nurgiyantoro, Dasar-Dasar Pengembangan Kurikulum Sekolah (Yogyakarta: BPFE, 1998), 11.

${ }^{5}$ Ibit, 11.
} 
konperhensif terapadu bagi siswa berdasarkan tujuan yang telah ditetapkan dalam kurikulum. ${ }^{6}$

Keterampilan membaca bukan keterampilan yang otomatis atau sederhana dan bukan juga proses pembelajaran yang membutuhkan sedikit waktu. Sesungguhnya keterampilan membaca merupakan dasar pemikiran otak yang intuitif. membaca merupakan proses mental, dan didalam membaca terdapat rumus secara tertulis yang terdiri dari huruf, harkat dan struktur untuk memahami makna dari teks yang dibaca.

Cooperative Integrated Reading and Compositian (CIRC) adalah salah satu model pembelajaran cooperative learning yang pada mulanya merupakan pengajaran kooperatif terpadu membaca dan menulis yaitu sebuah program komprehensif atau luas dan lengkap untuk pengajaran membaca dan menulis untuk kelas-kelas tinggi sekolah dasar. Fokus utama kegiatan CIRC adalah membuat penggunaan waktu menjadi lebih efektif. Siswa dikondisikan dalam tim-tim kooperatif yang kemudian dikoordinasikan dengan pengajaran kelompok membaca, supaya memenuhi tujuan lain seperti pemahaman membaca, kosa kata, pembacaan pesan, dan ejaan. Dengan begitu siswa termotivasi untuk saling bekerja sama dalam sebuah tim. ${ }^{7}$

\section{Metode Penelitian}

Peneliti mengunakan metodologi penelitian Research and Development (R\&D), metodologi ini merupakan cara yang dipakai untuk mencapai hasil yang spesifik dan ujicoba yang efektif. ${ }^{8}$ Metodologi ini menggunakan teori Borg and Gall yang mana ada sepuluh langkah-langkah dalam penelitiannya, yaitu: ${ }^{9}$ 1.Melakukan penelitian pendahuluan, 2.Melakukan perencanaan yaitu identifikasi dan definisi keterampilan, 3. Mengembangkan jenis/ bentuk produk awal meliputi: penyiapan materi pembelajaran, penyusunan buku petunjuk, dan perangkat evaluasi, 4.Melakukan uji coba tahap awal, 5.Melakukan revisi terhadap produk utama, 6.Melakukan uji coba lapangan utama, 7.Melakukan revisi terhadap produk operasional, 8.Melakukan uji lapangan operasional, 9.Melakukan perbaikan terhadap produk akhir, 10.Mendesiminasikan dan mengimplementasikan produk. berikut:

Penelitian pengembangan dilakukan dengan langkah-langkah sebagai

1. Melakukan penelitian pendahuluan: peneliti mengobservasi ketika pembelaajaran Qiro'ah sedang berlangsung, dan penelitti menemukan sebaagian permasalahan, diantaranya: buku ajar yang digunakan masih tradisional karena hal tersebut ketika proses pembelajaran Qiro'ah siswa merasa bosan. kemudian peneliti melakukan wawancara terhadap guru Qiro'ah hasil dari wawancara tersebut siswa diharuskan supaya cepat memehami bahasa arab akan tetapi buku ajar yang digunakan masih

\footnotetext{
${ }^{6}$ Rosyid Ahmad Tuaimah, Al-Luha Al-arobiya Linnatikin billlughot Ukhro, (Jami'ah Al-Um Alqura: Ma'had Al-Lughah Al-Arobiyah tampa ada tahun penerbit), 202.

${ }^{7}$ Robert E. Slavin, Cooperative Learning Teori, Riset dan Praktik, (Bandung: Nusa Media,2010), 200.

8Dukan Ubaidat dkk, Al-bahsi Al-ilmi: Mafhumihi wa asalibihi, (Amman: Darul Fikri, 1992 M), 282.

${ }^{9}$ Nana Syaodih Sukmadinata, Metode Penelitian Pendidikan (Bandung: PT, 2015), 169-170.
} 
tradisional. Didalamnya tidak terdapat tujuan khsus dalam pembelajaran, setelah itu peneliti membagikan angket kepada siswa untuk data analisis kebutuhan. hasil dari angket yang sudah diberikan bahwa siswa menginginkan buku ajar yang terdapat didalamnya gambar dan warna

2. Pengumpulan referensi dan pengembangan bentuk desain produk: pada langkah ini peneliti mengumpulkan referensi dari bermacam-macam buku yang berhubungan dengan materi ajar yang akan dikembaangkan,

3. Desain buku ajar: peneliti mengajukan beberapa judul bahan ajar yang ingin dikembangkan kepada guru bahaasa arab di sekolah tersebut. Judul yang di sepakati yaitu "Ayo Belajar Bahasa Arab". Terdapat tiga tema dalam materi ajar yaitu: Alamat, Rumahku dan Aktifiitas keluarga. Desain buku ajar yang akan dikembangkan sebagai berikut: Lembar sampul, tujuan pembelajaran, kosa kata, teks Qiro'ah, latihan soal, tata bahasa dan permainan.

4. Validasi ahli: validasi dilakukan oleh dua ahli yaitu ahli desain dan ahli bahasa. Hasil validasi materi ajar yang dilakukan ahli desain yaitu $80 \%$ yang berarti baik, kemudian pengembang memperbaiki produk berdasarkan catatan dari ahli desain. Adapun hasil validasi materi ajar yang dilakukan ahli bahasa yaitu $84 \%$ yang berarti sangat baik.

5. Revisi produk: Penneliti memperbaiki produk sesua dengan arahan yang terdapat pada catatan lembaran ahli

6. Melakukan uji coba lapangan utama: peneliti melakukan uji coba terpadu terhadap empat siswa dari sembilan belas siswa yang ada, dan hasilnya 32 dengan rata-rata 8 yang berarti peneliti diperbolehkan untuk menggunakan meteri ajar yang dikembangkan ke langkah selanjutnya yaitu uji coba efektivitas produk.

7. Revisi produk: pada langkah ini peneliti merevisi produk berdasarkan uji coba terpadu

8. Uji coba efektivitas produk: pada langkah penelitian ini peneliti menggunakan uji coba pre-tes dan Post-tes. yang mana uji coba dilaksanakan dengan menggunakan produk materi ajar yang dikembangkan ketika pembelajaran Qiro'ah.

9. Revisi produk: pada langkah ini peneliti memperbaiki produk berdasarkan hasil uji coba efektivitas.

10. Mempublikasikan materi ajar yang telah dikembangkan, pada langkah ini peneliti meminta kepada guru bahasa arab agar mempublikasikan materi ajar yang sudah dikembangkan kepada siswa.

Karekteristik materi ajar yang dikembangkan Judul buku: "ayo belajar bahasa arab". Tema materi ajar yang dikembangkan yaitu: Alamat, Rumahku dan Aktifitas keluarga. Model pembelajaran Cooperative Integrated Reading and Composition (CIRC). Hasil efektivitas penggunaan materi ajar yang sudah dikembangkan dari jumlah keseluruhan nillai pre-test dan Post-tes terhadap 19 siswa yaitu efektif dengan melalui hasil uji wilcoxon sebagai ganti dari pada uji -t 
Ranks

\section{Uji wilcoxon (alternatif dari uji-t)}

\begin{tabular}{|ll|l|l|l|}
\hline & & N & $\begin{array}{l}\text { Mean } \\
\text { Rank }\end{array}$ & $\begin{array}{l}\text { Sum of } \\
\text { Ranks }\end{array}$ \\
\hline & Negative & $0^{\text {a }}$ &, 00 &, 00 \\
post_test & Ranks \\
pre_test & Positive & $15^{\mathrm{b}}$ & 8,00 & 120,00 \\
& Ranks & $4^{\mathrm{c}}$ & & \\
& Ties & 19 & & \\
& Total & 19 & \\
\hline
\end{tabular}

a. post_test < pre_test

b. post_test $>$ pre_test

c. post_test $=$ pre_test

Interpretasi output uji Wilcoxon:

1. Negatif ranks antara pre-tes dan Post-tes adalah 0 , baik itu pada nilai $\mathrm{N}$, Mean, Rank, maupun Sum Rank. Nilai 0 ini menunjukkan tidak adanya penurunan dari nilai pre-tes ke nilai Post-tes

2. Positif ranks antara pre-tes dan Post-tes. Di sini terdapat 15 yang artinya 15 siswa mengalami peningkatan. Man Frank atau rata-rata peningkatan tersebut adalah sebesar 8,00 sedangkan jumlah ranjing positif atau aum of ranks sebesar 120,00.

3. Ties adalah kesamaan nilai pre-tes dan Post-tes, di sini nilai ties adalah 4, sehingga dikatakan terdapat 4 nilai yang sama antara pre-post

Dasar pengambilan keputusan dalam uji wilcoxon:

1. Jika nilai Asymp.sig.(2tailed) lebih kecil dari $<0,05$, maka Ha diterima

2. Sebaliknya, jika nilai Asymp.sig.(2tailed) lebih besar $>0,05$ maka Ha ditolak

\section{Test Statistics ${ }^{a}$}

\begin{tabular}{|l|l|}
\hline & $\begin{array}{l}\text { post_test } \\
\text { pre_test }\end{array}$ \\
\hline $\begin{array}{l}\text { Z } \\
\text { Asymp. Sig. (2- } \\
\text { tailed) }\end{array}$ & $\begin{array}{l}-3,424^{\mathrm{b}} \\
001\end{array}$ \\
\hline
\end{tabular}

a. Wilcoxon Signed Ranks Test

b. Based on negative ranks.

Berdasarkan output di atas diketahui Asymp.sig.(2tailed) bernilai 0,001 karena nilai 0,001 lebih kecil dari <0,05 maka disimpulkan Ha diterima, artinya ada perbedaan yang signifikan antara pre-test dan Post-tes. Dengan hasil tersebut penggunaan materi ajar yang telah dikembangkan yaitu Materi Berbasis Cooperative Integrated Reading and Composition (CIRC) untuk Kemahiran Membaca efekif dalam pengembangan kemampuan Qiro'ah siswa.

\section{Kesimpulan}

Pengembangan materi ajar ini dilakukan dengan langkah-langkah sebagai berikut: 1.Melakukan penelitian pendahuluan, 2.Pengumpulan referensi dan pengembangan bentuk desain produk, 3.Desain buku ajar, 4.Validasi ahli, 5.Revisi 
produk, 6.Melakukan uji coba lapangan utama, 7.Revisi produk, 8.Uji coba efektivitas produk, 9.Revisi produk, 10.Mempublikasikan materi ajar yang telah dikembangkan, dengan langkah-lagkah diatas dihasilkan pengembangan materi ajar Qiro'ah berbasis Cooperative Integrated Reading and Composition (CIRC) untuk MTs Tanwirul Islam yaitu materi ajar yang disajikan dalam bentuk pengelompokan dengan desain lembar sampul, tujuan pembelajaran, kosa kata, teks Qiro'ah, latihan soal, tata bahasa dan permainan. Hasil penggunaan materi ajar ini menunjukkan bahwa materi ajar Qiro'ah dapat meningkatkan hasil belajar siswa dengan hasil dari Asymp.sig. (2tailed) bernilai 0,001 karena nilai 0,001 lebih kecil dari <0,05 maka disimpulkan Ha diterima, artinya ada perbedaan yang signifikan antara pre-test dan Post-tes. yang artinya materi ajar yang dikembangkan memiliki pengaruh yang sangat besar (signifikan) atau sangat efektif untuk keberhasilan pembelajaran Qiro'ah.

Harapan peneliti: 1.Peneliti berharap produk materi ajar yang dikembangkan bisa digunakan siswa dalam pembelajaran bahasa arab khususnya pembelajaran Qiro'ah, 2.Peneliti berharap kepada guru agar membaca terlebih dahulu petunjuk penggunaan materi ajar yang telah dikembangkan yaitu pembelajaran Qiro'ah dengan model Cooperative Integrated Reading and Composition (CIRC), 3.Peneliti berharap kepada guru agar mengikuti semua petunjuk yang terdapat pada produk yang telah dikembangkan sebelum menggunakannya dalam pembelajaran Qiro'ah, 4.Peneliti berharap kepada para guru agar memperbanyak latihan-latihan kepada siswa dalam pembelajaran Qiro'ah, 5.Peneliti berharap kepada para guru agar pembelajaran Qiro'ah menggunakan model Cooperative Integrated Reading and Composition (CIRC).

\section{Daftar Pustaka}

Ahmad Warson Munawir dan Muhammad Fairuz, Al- Munawwir: Kamus IndonesiaArab (Yogyakarta: Pustaka progresif, 2007).

Burhan Nurgiyantoro, Dasar-Dasar Pengembangan Kurikulum Sekolah (Yogyakarta: BPFE, 1998).

Dukan Ubaidat dkk, Al-bahsi Al-ilmi: Mafhumihi wa asalibihi, (Amman: Darul Fikri, $1992 \mathrm{M}$ )

Nana Syaodih Sukmadinata, Metode Penelitian Pendidikan (Bandung: PT, 2015).

Robert E. Slavin, Cooperative Learning Teori, Riset dan Praktik, (Bandung: Nusa Media,2010),

Rosyid Ahmad Tuaimah, Al-Luha Al-arobiya Linnatikin billlughot Ukhro, (Jami'ah Al-Um Al- qura: Ma'had Al-Lughah Al-Arobiyah tampa ada tahun penerbit)

Toha Ali Husin Addalimiy wa Sa'ad Abi Al-karim Al-Waliy, Ittijahat hadisati fi tadrisAa-Luuhha Al-Aarobiyah, (Al- Ardan: Alimu Al-kitab Al-hadist, 2009) 